\title{
Flexible versus Designated Technologies and Inter-Fuel Substitution
}

\author{
Alain Bousquet ${ }^{\text {and }}$ Norbert Ladoux y
}

May 13, 2004

\begin{abstract}
A bstract
Zero demands for some types of energy are frequently observed in ..rm level data sets. To deal with this problem, two alternative solutions are retained in the literature: ..rstly, it can be assumed that the consumption of some kinds of energy is not allowed by the existing technology; secondly one can suppose that ..rms decide to use only some of the dixerent kinds of energy allowed by the technology. In this paper we estimate the inter-fuel substitutions resulting from these two dixerent situations. We take into account that increasing the price of an energy form possibly modi..es the number of energy used by the ..rm. We show that even in this case an estimation of the elasticity of substitution can be obtained. The empirical results are based on a French manufacturing energy consumption survey.
\end{abstract}

K ey words : E nergy demand, Censored regression, Inter-fuel substitution

J EL Classi..cation : 022, 212, 631, 723

We are grateful to the Institut Français de l'E nergie for its ..nancial research support, and to the SESSI for making the data avalaible to us.

\footnotetext{
"University of Toulouse, CEA and LER NA 21 allée de Brienne, 31000 Toulouse Cedex, tel: (33) 5611285 91, fax: (33) 5611286 37, Email : bousquet@cict.fr.

YUniversity of Toulouse, IDEI and LERNA 21 allée de Brienne, 31000 Toulouse Cedex, tel: (33) 5611285 90, fax: (33) 5611286 37, E mail : ladoux@cict.fr.
} 


\section{Introduction}

Firm-level panel data sets reveal a salient feature of energy consumption: the great variability of energy uses. Examples of this variability include simultaneous adoption and abandon of some energy forms and large dixerences in the level of energy consumption over time and across ..rms. This heterogenous behavior of ..rms with regards to energy consumption is observed even when relatively homogenous populations of ..rms are considered such as ..rms in the same industry.

Most of the published research on industrial energy demand makes use of aggregated data. A mong them the most often cited are Fuss (1977), Gric n (1977), Halvorsen (1977), Pindyck (1979), Hall (1983) and Magnus and Woodland (1987).

Studies making use of individual data have most often focused on the residential sector (see Madlener (1996) for a survey). W hile demand theory commonly deals with situations where the demand is continuously variable, empirical works on residential energy demand are based on continuousdiscrete choice models (Dubin and M cFadden (1984)). In this framework, the discrete fuel choice involves comparisons of indirect utility attached to various fuel systems. Consistent with the theory of consumer behavior, continuous equation describing energy use are derived from the indirect utility function by using Roy's identity (Hanemann (1984)). For industrial energy demand the dic culty is similar but more severe because ..rms choose dixerent fuel patterns (i.e. dixerent combinations of dixerent types of energy). As noted by Woodland (1993), the possibility of corner solutions leading to one or more zero values of some types of energy, can occur as a result of two alternative situations. First, dixerent fuel patterns are determined by previous technology choice. In that case, for a given technology, some energy forms are required while other are not allowed. Firm behavior in the short run is restricted to the subset of energy forms allowed by ...rms' technology. Later in the paper we will call such a case "designated technology" where zero demand are the result of an exogenous rationing ${ }^{1}$. This is precisely the hypothesis assumed by Woodland (op.cit.) who estimates "conditional" production functions, that means as many production functions as signi...cantly observed fuel patterns. Assuming that fuel patterns are the result of technological constraints, Bjorner and J ensen (2002) follow the same approach.

The second approach considers that zero consumptions may instead be the result of cost minimization behavior leading to a corner solution. In this framework all types of energy can potentially be used since the technology is $\ddagger$ exible enough to allow substitutions between energy forms. This case

\footnotetext{
${ }^{1}$ Given previous choice about the technology, ex-post the ..rm is like in a situation of exogenous rationing as some energy forms are not used whatever the level of energy prices.
} 
will be called hereafter " $¥$ exible technology"; zero demand is the result of an endogenous rationing. Both multiple-..red equipment and redundant or backup equipment can contribute to the switching capabilities between dixerent kinds of energy. Then, if there is no switching costs, one or more energy forms cannot be used when their prices are suф ciently high relative to their marginal contribution to output. Lee and Pitt (1987) and more recently, B ousquet and al (1989) and (1998) develop such a model and apply it on individual ..rms' data.

The objective of this paper is to compare the dixerences in estimated inter-fuel substitution possibilities as measured under the two alternative assumptions about the energy technology leading to an energy demand system with ex-post exogenous or endogenous rationing.

In section 2 we present the data base used in the econometric analysis. The two possible assumptions about energy technology are discussed in light of some empirical evidence. Section 3 deals with the two theoretical models and shows how signi..cant is the dixerence between the two modelling approaches. Section 4 and 5 are ..nally devoted to the empirical part of the analysis.

\section{Heterogeneity in energy technology}

Depending on energy market conditions and plant characteristics, energy technologies dixer by their input requirement set. The energy technology is a varied collection of equipment, like boilers, ovens, heating apparatus, power engines, steam generators, ... designed to consume a single fuel or a combination of fuels. As a result, a given energy technology allows for a certain fuel substitution capability.

As noted by Doms(1993) the literature on energy technology for manufacturing plants is scant. W ithout knowledge about plant's energy technology characteristics and the link with energy use, it is nevertheless possible to consider two extreme assumption corresponding to either designated or fexible technology. It is then possible to explore one aspect of the manufacturing response to shocks in energy price and to highlight the importance of technology assumptions made in energy demand modelling.

\subsection{Data description}

The data set for this study is a cross-section of establishments built from the "E nquête A nnuelle sur les Consommations d'E nergies de I'I ndustrie". A general description of the energy survey and global statistics about energy consumption in the french industry are provided in the annual publication of the Ministère de I'Industrie (see SESSI (1997)). The data set includes approximately 13,000 observations. The survey reports energy consumptions for 11 kinds of energy ( 3 types of coal or coke, 3 types of gas, 2 types of oil, 
electricity, heating, and others energies like wood, wastes,...). T he quantity of energy consumed is measured in toe and in current Euro. Then, the energy prices are obtained by calculating the ratio of values over quantities. That means that prices in our data set are average prices over one year. ${ }^{2}$ It should be recognized that average prices could be endogenous due to decreasing block pricing in relation with quantity consumed. But taking into account price endogeneity needs more information on ..rm's characteristics than we have. Moreover, prices does not depend on quantities consumed only, many other factors play an important role. A mong them, peak-load pricing and transportation costs are certainly the most important. But, in a short term perspective, they can be considered as exogenous since ..rm's location is given, as well as wether or not the ..rms work in twenty four hours shifts. Finally, as pointed out by Pudney (1989), in large samples, average prices could be considered as approximately exogenous.

In the current study we focus on the substitution between three dixerent energy inputs:

2 gas, a composite good including natural gas and lique..ed petroleum gas (LPG);

2 oil products, a composite good including heavy oil and domestic fuel oil;

2 electricity.

To measure electricity consumption by ...rms, we use electricity purchases; therefore, the own-production of electricity by ..rms is not taken into account in our study. Note that only $5 \%$ of plants produce electricity by their own.

We neglect ..rms that use coal, heating and other energy, since they are very few. The ..nal sample used for estimation includes 12745 observations.

From table 1 we can deduce the percentage of ..rms using a given form of energy. While all ..rms use electricity, only one half of the sample use oil and less than two third use gas.

One group of ..rms uses all the three types of energy. This group represents less than one third of plants in the industry. Note that, as a consequence, zero expenditure observations frequently occur in our sample. The major pattern is a mix between gas and electricity. The case where electricity is the only fuel or energy source used represents a signi..cant proportion of the sample (see table 1).

\footnotetext{
${ }^{2}$ Of course, prices are not observable when a zero demand occurs.
} 
Table 1: Frequency of fuel patterns

\begin{tabular}{lc}
\hline \hline \multicolumn{1}{c}{ Fuel pattern } & Frequency \\
\hline \hline gas, oil and electricity & $27 \%$ \\
gas and electricity & $38 \%$ \\
oil and electricity & $21 \%$ \\
electricity & $14 \%$
\end{tabular}

\subsection{Fuel pattern and assumption about the energy technol- ogy}

Bjorner and J ensen (2002) observe that companies over time do not change frequently from one fuel pattern to another, and use this ..nding to justify the Woodland approach, assuming that fuel patterns are given in the short term. The point of view is dixerent in the empirical study of Doms (1993), who shows clearly that ..rms could change rapidly their energy technologies and that a signi...cant part of the technologies are $\ddagger$ exible. M oreover, the analysis based on the U. S. M anufacturing Energy Consumption Survey (henceforth MECS, see D OE/ IEA (1994)), provides empirical evidence about the ability of ..rms to switch between dixerent kinds of energy in the short run without changing the technology. In 1991, for instance, around $20 \%$ of manufacturing plants possess some capability to switch. The same year, the total capability to switch is estimated at 2.8 quadrillion Btu, that is $14 \%$ of the primary energy consumption in the manufacturing sector (which amounts to 20.3 quadrillion Btu). If necessary, $20 \%$ of Distillate Fuel Oil consumption could be replaced by other energy sources, this proportion is greater than $40 \%$ for LPG, coal and residual fuels. Natural gas appears to be an intermediate case with $35 \%{ }^{3}$

This empirical evidence shows that substitution possibilities among energy sources could be very high for a minor but signi..cant part of the industry and energy consumption. Switching capability is an important dimension of heterogeneity in energy technologies. For energy demand modelling the consequence is that Woodland (1993) and Lee and Pitt (1987) are at the same time right and wrong, because a zero consumption for one kind of energy can be the result of an ex-post exogenous rationing as well as of an endogenous rationing, depending on the characteristics of the energy technology.

\footnotetext{
${ }^{3}$ For the MECS, manufacturers are said to have a fuel-switching capability if they are able to meet their requirements for heat, power and electricty generation by substituting one energy source for another within 30 days without modifying the equipment that consumes the fuel and resuming the same level of production following the switch.
} 


\section{M odels for inter-fuel substitution}

\subsection{M ain assumptions}

Following Hudson and J orgenson (1974) and Griф $n$ (1977), we assume that the dixerent energy inputs make up a separable and homogeneous energy aggregate. For this study, we are obliged to make this hypothesis since data on other inputs than energy, and output of the ..rms are unavailable. Stated alternatively, we are making an analysis focusing on substitution possibilities between the dixerent kinds of energy and we do not take into account others forces driving energy demand. The substitution elasticities inside the energy aggregate are independent of inputs prices outside the aggregate and also independent of the production level. These assumptions allow us to estimate separately the unit cost function of energy. Formally our model assumes that the cost function is weakly separable between energy and the others inputs.

The ..nal step toward the speci..cation of the econometric model is the choice of a functional form to represent the energy technology. A mong the most popular $\ddagger$ exible forms (the translog, generalized Leontief and symmetric generalized McFadden), the translog is clearly the most convenient in particular because it leads to a tractable econometric model in a context where the decision variables are censored ${ }^{4}$.

The three kinds of energy inputs included in our model are indexed $\mathrm{i}=1 ; 2 ; 3 .^{5} \mathrm{p}_{\mathrm{i}}$ and $\mathrm{x}_{\mathrm{i}}(\mathrm{i}=1 ; 2 ; 3)$ are respectively the price and the quantity consumed of energy $i$. The total cost of energy is given by,

$$
p_{E} E=p_{i=1 ; 2 ; 3}^{X} p_{i} x_{i}
$$

where $p_{E}$ and $E$ denotes respectively the price index and the quantity index of the energy aggregate. Finally ${ }_{i}(i=1 ; 2 ; 3)$ are disturbance terms assumed to be distributed $\mathrm{N}(0 ; \S)$.

The translog form of the unit cost function of energy, $p_{E}=C_{E}\left(p_{1} ; p_{2} ; p_{3}\right)$, is then given by,

$$
\ln \left(p_{E}\right)=\otimes_{0}+X_{i=1}^{X_{i}} \ln p_{i}+\frac{1}{2} X_{i=1 j=1}^{3} X^{3}-i_{j} \ln p_{i} \ln p_{j}+X_{i=1}^{X^{3}} "_{i} \ln p_{i}
$$

where,

\footnotetext{
${ }^{4}$ O ur analysis could be made with other quadratic ‡exible forms, but at a higher cost in term of estimation. The existing comparison between $\ddagger$ exible functional forms concerns monotonicity and concavity restrictions (see Terrel (1996)), not the properties with respect to zero demands.

${ }^{5}$ Energy 1,2 and 3 are respectively gas, oil and electricity.
} 


$$
-_{i j}={ }_{j i} 8 i ; j=1 ; 2 ; 3:
$$

The linearly homogenous property in input prices of the unit cost function implies the following additional parameters restrictions,

$$
X_{i=1}{ }^{\beta}=1 ;{ }_{j=1}^{X}-{ }_{i j}=0 \quad 8 i=1 ; 2 ; 3:
$$

From Shepard's lemma the value share of inputs are given by,

$$
w_{i}=\otimes+X_{j=1}^{X^{3}}-{ }_{i j} \ln p_{j}+"_{i} \quad i=1 ; 2 ; 3:
$$

Notethat under (2) and (3), we necessarily have ${ }_{i=1}^{P B}{ }_{i}=0$ and ${ }_{i=1}^{P B} w_{i}=1$.

\subsection{The case of designated technologies}

Following Woodland (1993), we assume here that observed fuel patterns are simply the consequence of a previous choice among a set of designated technologies. This previous choice restricts the set of energy forms that can be used. Then the problem of the ..rm is to determine the optimal allocation of its energy needs over a given subset of the dixerent kinds of energy.

\subsubsection{The technology allows the ..rm to use all energy forms}

The parameters of the translog unit cost function (1) are estimated using the Zellner iterative method applied to the system of cost share equations,

$$
\begin{aligned}
& \mathrm{w}_{1}=\mathbb{B}_{1}+{ }^{-}{ }_{11} \ln \frac{\mathrm{p}_{1}}{\mathrm{p}_{3}}+{ }^{-}{ }_{12} \ln \frac{\mathrm{p}_{2}}{\mathrm{p}_{3}}+{ }_{1} ; \\
& \mathrm{w}_{2}=\mathbb{B}_{2}+{ }^{-}{ }_{12} \ln \frac{\mathrm{p}_{1}}{\mathrm{p}_{3}}+{ }^{-}{ }_{22} \ln \frac{\mathrm{p}_{2}}{\mathrm{p}_{3}}+{ }_{2}:
\end{aligned}
$$

Table 2 below gives the empirical results. 
Table 2: Estimation when all energy forms are used

\begin{tabular}{|c|c|c|}
\hline parameter & estimate & standard error \\
\hline$\overline{\mathbb{R}_{1}}$ & 0.24 & 0.0140 \\
\hline $\mathbb{B}_{2}$ & 0.11 & 0.0123 \\
\hline- & -0.23 & 0.0273 \\
\hline$-\begin{array}{l}11 \\
12\end{array}$ & 0.14 & 0.0191 \\
\hline$q^{22}$ & -0.17 & 0.0247 \\
\hline $\mathrm{E}^{112^{4}}$ & 0.17 & 0.0129 \\
\hline $\mathrm{E}^{\mathrm{I}_{12}}{ }^{\mathrm{E}}$ & 0.18 & 0.0111 \\
\hline$E(" 1 " 2)$ & -0.20 & 0.0122 \\
\hline
\end{tabular}

\subsubsection{The technology excludes one form of energy}

The translog unit cost function of energy includes only 2 types of energy. Consequently, the system of value share equations is reduced to a single equation,

$$
w_{i}=\otimes_{i}+{ }^{-} i \mathrm{ln} \frac{p_{i}}{p_{3}}+{ }^{i} ;
$$

where $\mathrm{i}=1$ when gas is excluded and 2 when oil is excluded.

The empirical results are given in table 3 and 4.

Table 3: Estimation when oil is excluded

\begin{tabular}{lrr}
\hline \hline parameter & estimate & standard error \\
\hline \hline $\mathbb{R}_{1}$ & 0.26 & 0.0124 \\
$\overline{\mathrm{q}} \frac{11}{\mathrm{E}} \mathrm{I}_{1}^{\mathrm{I}}{ }_{1}^{4}$ & -0.20 & 0.0325 \\
& 0.14 & 0.0070
\end{tabular}

Table 4: Estimation when gas is excluded

\begin{tabular}{lrr}
\hline \hline parameter & estimate & standard error \\
\hline \hline$\AA_{2}$ & 0.25 & 0.0199 \\
$-\mathrm{q}^{22}$ & -0.14 & 0.0382 \\
$\mathrm{E}{ }_{1{ }_{2}{ }_{2}}^{\ddagger}$ & 0.16 & 0.0099
\end{tabular}

\subsubsection{The technology excludes two forms of energy}

In this case there is no need for an econometric estimation; the only energy used is electricity (energy 3 ) then, $w_{1}=w_{2}=0$ and $w_{3}=1$ : 


\subsection{The case of a $\neq$ exible technology}

With a fexible technology, each ..rm is able to meet its requirements for heat, power etc. by substituting one energy form for another without modifying the equipment that consumes the fuel and obtaining the same level of production after the switch. The łexible technology assumption corresponds to the case where the energy technology allows the ..rm to change one kind of energy by another kind of energy at no $\operatorname{cost}^{6}$ and for a constant production level. In this case a zero demand for one or more energies is the result of an endogenous rationing. Following Wales and Woodland (1983) and later on Lee and Pitt (1986) and (1987), the approach to the zero corner solution problem is based on the use of virtual prices. Virtual prices are those prices at which non-negativity constraints on input demands solve the analogous unconstrained cost minimization problem; in other words, they are prices at which the ..rm would be on the margin of consuming non used inputs. At that prices, the so called "notional" demand of input and the observed demand are the same whatever the observed demand is. If the market price is higher than the virtual price, the notional input demand is negative, which results in zero observed demand. ${ }^{7}$ This approach characterizes a fuel pattern by a set of inequality and equality conditions where for each zero demand virtual prices are lower than market prices and respectively for each positive demands virtual prices and market prices are the same.

A complete treatment of the theory of virtual prices can be found in Neary and Roberts (1980) and in Pudney (1989). Their models provide directly the econometric speci..cation which enters the generalized Tobittype model. The main dixerence with a multiple censored regression is that virtual prices are endogenous thresholds explaining zero demands. These thresholds depend on the parameters of the model and are speci..c to each fuel pattern.

To derive the likelihood function for this model, we need to distinguish the dixerent fuel patterns. A fuel switching technology could lead to $2^{3} i 1=$ 7 possible fuel patterns. As all ..rms in the sample use electricity we may observe $2^{3 i}{ }^{1}=4$ fuel patterns only. To characterize these 4 dixerent cases, we introduce the following notations:

$2 w_{i}$ and $w_{i}$ are respectively the observed and the notional value shares of input;

$2 P_{E}^{X X X}$ is the unit cost of energy when all energy forms are used ( $X X X$ means gas, oil and electricity are used);

\footnotetext{
${ }^{6}$ Excepted of course the dixerence between the cost of energy purchase after and before the switch.

${ }^{7}$ In this paper, since we use a translog speci...cation of the unit cost function, we estimate value share of inputs. Thus, the dixerent fuel patterns will be characterized through the concept of notional value share of input instead of notional demand of input.
} 
$2 \mathrm{P}_{\mathrm{E}}^{\mathrm{OXX}}, \mathrm{P}_{\mathrm{E}}^{\mathrm{X} O \mathrm{X}}$ and $\mathrm{P}_{\mathrm{E}}^{\mathrm{OOX}}$ are similarly de..ned ("O" means not used).

\subsubsection{Fuel pattern $X X X$ : No binding non negativity constraint}

This case corresponds to an interior solution of the producer's optimization program. All types of energy are used, then notional demands coincide with observed demands, from (4) we have,

$$
\mathbb{H}_{i}\left(p_{1} ; p_{2} ; p_{3}\right)^{\prime} w_{i}=\otimes_{i}+{ }_{j=1}^{X^{3}}-{ }_{i j} \ln p_{j}+{ }_{i} \quad 8 i=1 ; 2 ; 3:
$$

Similarly we have from (1),

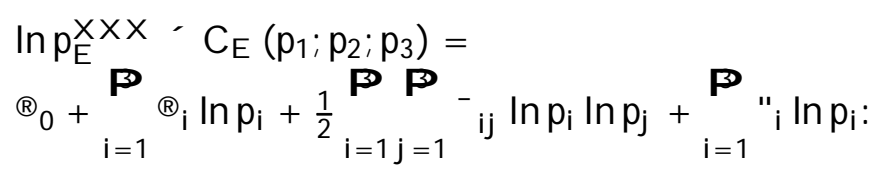

\subsubsection{Fuel patterns OXX or X OX: One binding non negativity} constraint

There is now one corner solution only. The observed zero demand is the result of an endogenous rationing. When zero demand occurs for input 1,8 the virtual price of input 1 , denoted by ${ }^{\prime}$, is solution to,

$$
\mathbb{G}_{1}\left({ }^{\prime} ; p_{2} ; p_{3}\right)=w_{1}=0:
$$

This fuel pattern occurs when the price of energy 1 is too high, the condition is, $p_{1},{ }_{1}$. Then in this case, provided that ${ }^{-}{ }_{11}<0$, it can be shown that we have $\mathbb{A}_{1}\left(p_{1} ; p_{2} ; p_{3}\right)<0$.

Substituting ' ${ }_{1}$ for $p_{1}$ into the notional cost share for input 2 and 3 de. ned by (5) gives after straightforward computations the analytical expression of the cost shares of input 2 and 3,

$$
\begin{aligned}
& \mathbb{H}_{2}\left({ }^{\prime}{ }_{1} ; p_{2} ; p_{3}\right)=w_{2}=\left(\mathbb{R}_{2}+{ }^{2} 2 i \frac{{ }^{-}}{=}{ }_{11}\left(\mathbb{1}_{1}+{ }^{2} 1\right)\right)+\left({ }^{-} 22 \mathrm{i} \frac{-{ }_{12}}{-}\right) \ln \frac{p_{2}}{p_{3}} ; \\
& \oplus_{3}\left({ }^{\prime}{ }_{1} ; p_{2} ; p_{3}\right)=w_{3}=1 ; w_{2} \text { : }
\end{aligned}
$$

Similar computations gives the expression of the unit cost function of energy for this fuel pattern ${ }^{9}$,

\footnotetext{
${ }^{8} \mathrm{~T}$ he case where zero demand occurs for input 2 can be derived by symetry.

${ }^{9} \mathrm{~V}$ irtual prices are used in the same way by Thomsen (2000) to determine the short run restricted cost function in a quasi-..xed capital model.
} 


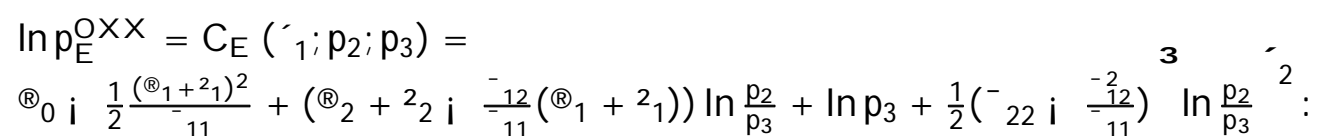

Note that the constant term of this conditional cost function comprises the term $\mathrm{i} \frac{1}{2} \frac{\left(\mathbb{B}_{1}+{ }^{2} 1\right)^{2}}{11}>0$ as ${ }^{-} 11<0$. This ref ects the cost of the binding non-negativity constraint on input 1 .

\subsubsection{Fuel pattern OOX: Two binding non negativity constraints}

We consider here the case with two corner solutions. The virtual prices of input 1 and input 2 are obtained by solving the simultaneous equations system,

$$
\begin{aligned}
& W_{1}\left({ }^{\prime}{ }_{1} ;{ }_{2} ; p_{3}\right)=w_{1}=0 \\
& \mathbb{W}_{2}\left({ }^{\prime}{ }_{1} ;{ }_{2} ; p_{3}\right)=w_{2}=0 ;
\end{aligned}
$$

and this fuel pattern occurs when prices for energy 1 and 2 are such that $p_{1},{ }_{1}$ and $p_{2},{ }^{\prime}$.

As input 3 is the only input used we necessarily have ${ }^{10}$

$$
w_{3}\left({ }^{\prime}{ }_{1} ;{ }^{\prime}{ }_{2} ; p_{3}\right)=w_{3}=1 .
$$

The energy unit cost function under OOX regime is given by the price of energy 3 up to a constant term,

$$
\begin{aligned}
& \ln \mathrm{p}_{\mathrm{E}}^{\mathrm{OOX}}{ }_{3}=\mathrm{C}_{\mathrm{E}}\left({ }^{\prime}{ }_{1} ;{ }^{\prime}{ }_{2} ; \mathrm{p}_{3}\right)= \\
& \mathbb{R}_{0} \text { i } \frac{1}{2} \frac{\left(\mathbb{B}_{1}+{ }^{2}\right)^{2-}{ }_{22 i} 2\left(\mathbb{B}_{1}+{ }^{2} 1\right)\left(\mathbb{R}_{2}+{ }^{2}\right)^{-}{ }_{12}+\left(\mathbb{(}_{2}+{ }^{2}\right)^{2-}{ }_{11}}{{ }_{11}{ }^{-22} i^{-}{ }_{12}^{2}}+\ln p_{3} \text { : }
\end{aligned}
$$

To understand why there is a constant term in (8), we must remember that when the only input used is input 3, the optimal demands for input 1 and 2 are negative. Then, zero demands for input 1 and 2 are not necessarily optimal in our model. The constant in (8) refects the cost resulting from the fact that the non negativity constraints on input 1 and 2 are binding.

\subsubsection{Estimation}

The estimation is based on the method of maximum likelihood. Our model is a discrete/ continuous choice model but, contrary to most of the models of this type, the discrete choice (the choice of the fuel pattern) and the

\footnotetext{
${ }^{10}$ Of course, substituting the expressions giving virtual prices for input 1 and 2 into the notional cost share for input 3 gives $w_{3}=1$.
} 
continuous choice (the level of demand) are here derived from the same cost minimization problem. Consequently, the decision rules for the discrete and continuous choices depend on the same set of parameters and errors terms.

Following Van Soest and Kooreman (1990), it is well known that this econometric model is correctly speci..ed only if certain coherency conditions are satis..ed. In generalized Tobit models, a model is de..ned to be coherent if, for each possible values of the regressors and the errors terms, there exists a unique value for the endogenous variables. Coherency is clearly a minimal requirement for model speci..cation. For binding non-negativity constraint, Van Soest and Kooreman show that coherency conditions are necessarily satis..ed when the cost function is globally concave. In our case, the cost shares and fuel pattern are unambiguously de..ned and the likelihood function is well de..ned over the disjoint regimes of demand.

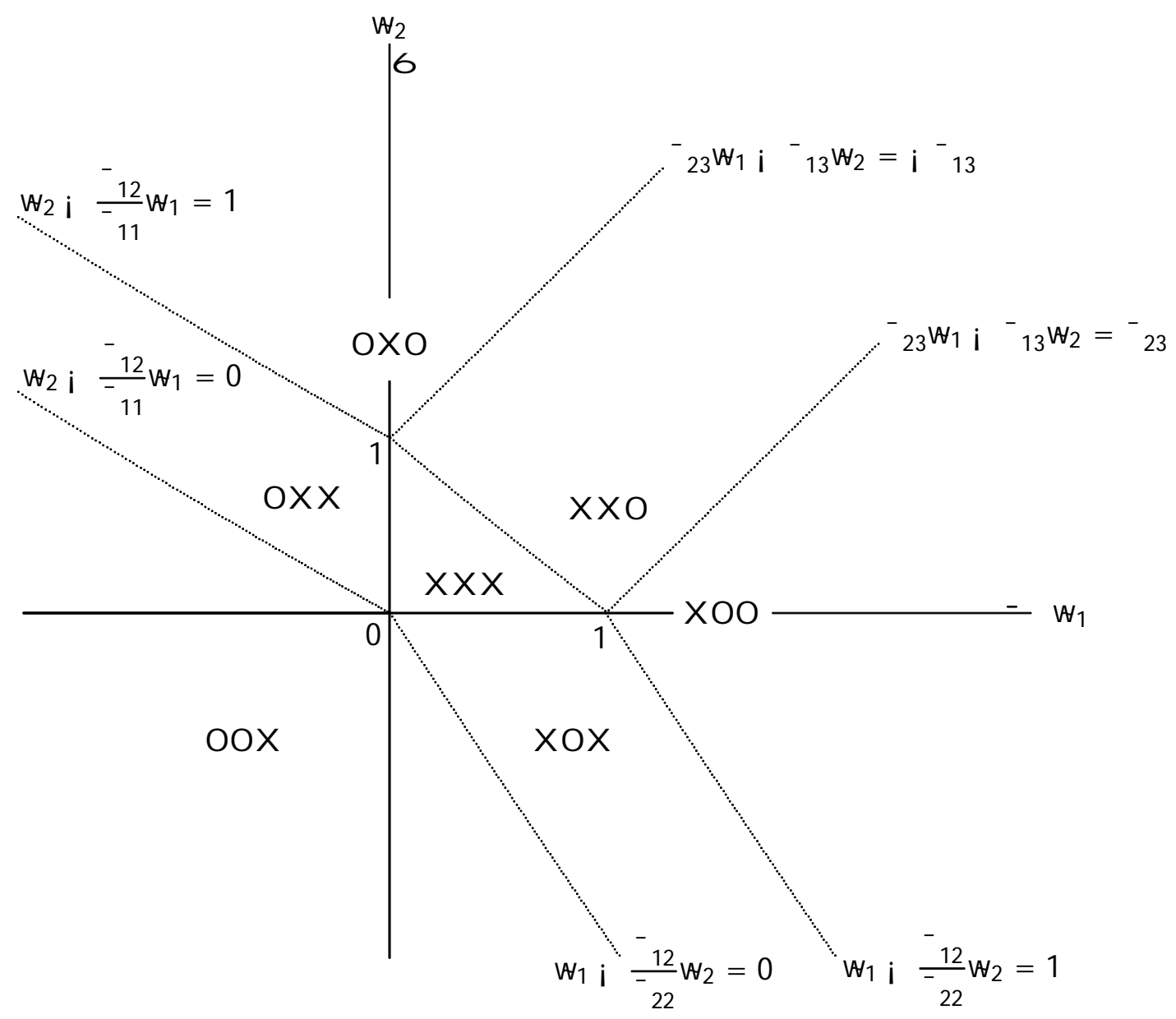

Figure 1 Coherency conditions.

Figure 1 is like a map of the dixerent fuel pattern, given possible values of notional cost shares. Another look at coherency conditions could be 
provided by the comparison of conditional unit cost functions across the dixerent fuel patterns. It is easy to show that coherency conditions ensure that ..rms are able to minimize cost over the dixerent fuel patterns. As a consequence, the ..rm can choose a (unique) fuel pattern corresponding to the lower cost among the set of alternatives. This means that we need a globally concave cost function to be sure that the discrete choice model gives us the optimal cost (see Blundell and Smith 1994).

We do not illustrate here the way to build the likelihood function of this model, a complete description is given by Bousquet and Ivaldi (1998). As in generalized Tobit models, the likelihood function involves for each fuel pattern the product of a probablility and a conditional density function corresponding to the discrete and continous choice among the three energies we consider. A ssuming a bivariate normal distribution for the additive error terms in the relative costs shares $\left({ }^{2}{ }_{1} ;{ }^{2} 2\right)$, the likelihood function could be written in a closed form.

As the prices associated to zero demands are not observable, we need an additional hypothesis. We consider that non-observed prices are equal to the maximum price from the observed distribution of energy prices. ${ }^{11}$

Table 5 : Estimation results for a ł exible technology

\begin{tabular}{|c|c|c|}
\hline$\overline{\text { parameter }}$ & estimate & standard error \\
\hline $\mathbb{R}_{1}$ & $\overline{0.22}$ & 0.0028 \\
\hline $\mathbb{B}_{2}$ & 0.01 & 0.0033 \\
\hline- & -0.47 & 0.0073 \\
\hline-12 & 0.26 & 0.0077 \\
\hline $\bar{q}^{22}$ & -0.51 & 0.0076 \\
\hline $\mathrm{E} .12^{4}$ & 0.21 & 0.0036 \\
\hline$\left.E\right|_{112} ^{4}$ & 0.23 & 0.0046 \\
\hline$E(" 1 " 2)$ & -0.50 & 0.0228 \\
\hline
\end{tabular}

As in the previous estimations, all the parameters are here highly significant. A nother way to check the quality of the estimates is to compare the observed fuel patterns with the one predicted by the model. Table 6 below shows that the prediction is globally acceptable; $98 \%$ of ..rms using a mix of gas and electricity and $94 \%$ of ..rms using a mix of oil and electricity are correctly predicted.

The prediction is less good for ..rms using all the three energy inputs, since only $39 \%$ of these ..rms are predicted in this fuel pattern. For these

\footnotetext{
${ }^{11} \mathrm{~A}$ similar solution is taken in labor supply models where the wage for an unemployed is taken as the minimum value found in the observed wage distribution. Here, we have replicated the estimation when, instead of the maximum price, we use the upper centile of the price distribution; we have found very little dixerences in the estimation results.
} 
..rms, the model often predicts that the optimal fuel pattern is a mix between gas and electricity. When electricity is the unique energy source the prediction is only correct for $56 \%$; $44 \%$ of ..rms using electricity alone are predicted to use also oil.

Table 6: Predicted fuel patterns vs observed one

\begin{tabular}{l|rrrrr}
\hline \hline & \multicolumn{5}{|c}{ predicted patterns } \\
observed patterns & Gas+Oil+Elec. & Gas+Elec. & Oil+Elec. & Elec. & Total \\
\hline \hline Gas+Oil+Elec. & 1342 & 1675 & 429 & 25 & 3471 \\
Gas+Elec. & 34 & 4769 & 3 & 62 & 4868 \\
Oil+Elec. & 0 & 0 & 2526 & 168 & 2694 \\
Elec. & 9 & 0 & 747 & 956 & 1712 \\
Total & 1385 & 6444 & 3705 & 1211 & 12745
\end{tabular}

\section{Price Elasticities}

Price elasticities are de..ned by,

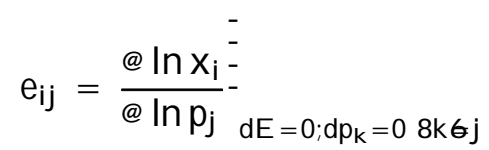

Using Shephard's lemma, it can be easily shown that (9) is equivalent to,

$$
e_{j}=\frac{p_{j} C_{i j}}{C_{i}} \quad 8 i ; j=1 ; 2 ; 3:
$$

where $C_{i}$ and $C_{i j}$ are respectively given by,

$$
\begin{aligned}
& c_{i}, \quad \frac{@ n p_{E}}{@ n p_{i}} ; \quad i=1 ; \not \pitchfork \$ ; 3
\end{aligned}
$$

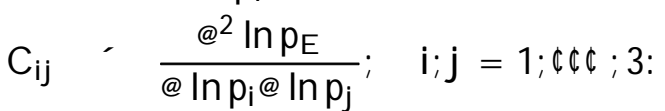

Using (10), straightforward computations show that in the translog case we have,

$$
\begin{aligned}
& e_{j}=\frac{-_{i j}+\hat{w}_{i} \hat{w}_{j}}{w_{i}} ; \quad i \epsilon j ; \\
& e_{i}=\frac{-\hat{w}_{i i}+\hat{w}_{i}^{2} \hat{W}_{i}}{\hat{w}_{i}} ;
\end{aligned}
$$


where $w_{i}$ is the expected value of the relative share of energy $i$.

We can easily use (11) and (12) to determine price elasticities in the case of a designated technology.

In the case of a łexible technology a marginal change of an input price can move consumption smoothly within a single fuel pattern, or yields to a drastic change in consumption when the ..rm changes its fuel pattern. This discontinuity of the demand behavior complicates signi..cantly the analytical expression of the price elasticities. Nevertheless, we can get an approximation of these elasticities. Our method is the following:

2 the observed price of a given energy form is increased at the margin;

2 this implies new values of the relative prices from which we can determine the optimal fuel pattern chosen by each ..rm ${ }^{12}$

2 the partial derivatives appearing in (10) are evaluated by using the GRADP and HESSP routines of the GAUSS software applied to the unit cost function given by (6), (7) or (8) depending on the fuel pattern the ..rm has chosen.

Tables 7 and 8 give the estimated price elasticities averaged over ..rms having the same fuel pattern under the hypothesis of designated and $\ddagger$ exible technologies respectively. Tables 9 and 10 give these elasticities averaged over the whole sample. ${ }^{13}$

Two main conclusions arise from tables 7 and 8. Firstly, it appears that inter-fuel substitution possibilities are higher for ..rms using the three energy forms compared to ..rms using two kinds of energy only, whatever the technology is supposed to be: designated or łexible. In table 7, oilprice elasticity is i $6: 83$ when ..rms use all kinds of energy while it is i $1: 36$ when ..rms use oil and electricity only. The same elasticities in table 9 are respectively i 11:50 and i 5:30.

Secondly, the two alternative models we use give very dixerent results about the substitution possibilities between energy forms. For instance, ownprice-elasticities for gas, oil and electricity are respectively i 1:81, i 6:83 and i 0:68 when ..rms have a designated technology while they are respectively i 5:23, i 11:50 and i 1:07 when ..rms have a łexible technology (this when all kinds of energy are used).

A last comment applies to both tables, oil is clearly much more sensitive to its own price than gas and electricity.

\footnotetext{
${ }^{12} \mathrm{As}$ few ..rms are located at the frontier between two fuel patterns, in practice a marginal increase in the energy price is not su $₫$ cient to induce a change in the fuel pattern. But, as we will see in the next section, this exect could be highligted for signi...cant changes in energy prices.

${ }^{13}$ Of course, when the fuel pattern is given, the price elasticity of an energy form not used by the ..rm is zero.
} 
Comparing tables 9 and 10 shows that in the model where the technology is considered as $\ddagger$ exible, the elasticities are, of course, bigger in absolute value, than in the model where the technology is considered as designated. The empirical $95 \%$ con..dence intervals of the elasticities appearing in tables 9 and 10 call for several remarks. First they are smaller in the designated case than in the fexible one. This of course is the result of the less constrained model we use in the $\ddagger$ exible case. Something strange, a priori, is the very high absolute value of the elasticities in some cases. This is a feature of the Translog model that the elasticities explode when factor share approches zero (see equations (12) (11)).

We can check on our sample that, for a given energy form, the larger is the elasticity (in absolute value) the smaller is the share of this kind of energy in the total energy consumption of the ..rm. It means that the elasticities do not allow to conclude from the point of view of how the industrial sector reacts, as a whole, to a variation of the relative energy prices. But aggregated ..rm's behaviour in response to relative energy price variations can be simulated as proposed in section 5 .

These simulations are also useful for another reason. We know that elasticities, by de.nition, give the input demand response to a marginal price increase. In the $\neq$ exible model, when a given price is increased only at the margin, the ..rms changing their fuel pattern are very few. Then, the estimation of price elasticities does not allow us to measure the consequences on energy demand of a drastic change in the relative prices of energy forms. Such a change is however possible, for instance to implement an energy policy aiming at reducing $\mathrm{CO}_{2}$ emissions.

Table 7: Price elasticities in the case of designated technologies within a given fuel pattern

\begin{tabular}{|l|c|c|c|c|c|c|c|c|c|}
\hline & \multicolumn{10}{|c|}{ fuel pattern } \\
\cline { 2 - 10 } & \multicolumn{2}{|c|}{ Gas+Oil+Electricity } & \multicolumn{2}{c|}{ Gas+Electricity } & \multicolumn{3}{|c|}{ Oil+Electricity } \\
\cline { 2 - 10 } & gas & oil & elec. & gas & oil & elec. & gas & oil & elec. \\
\hline Gas & i $1: 81$ & $0: 59$ & $1: 22$ & i $1: 45$ & - & $1: 45$ & - & - & - \\
Oil & $4: 01$ & i $6: 83$ & $2: 82$ & - & - & - & - & i $1: 36$ & $1: 36$ \\
Elec. & $0: 47$ & $0: 21$ & i $0: 68$ & $0: 62$ & - & i $0: 62$ & - & $0: 45$ & i $0: 45$ \\
\hline
\end{tabular}

Table 8: Price elasticities in the case of $\ddagger$ exible technologies within a given fuel pattern

\begin{tabular}{|c|c|c|c|c|cc|c|c|c|}
\hline & \multicolumn{10}{|c|}{ fuel pattern } \\
\cline { 2 - 10 } & \multicolumn{1}{|c|}{ Gas + Oil + Electricity } & \multicolumn{2}{|c|}{ Gas + Electricity } & \multicolumn{3}{c|}{ Oil + Electricity } \\
\cline { 2 - 9 } & gas & oil & elec. & gas & oil & elec. & gas & oil & elec. \\
\hline Gas & i $5: 23$ & $2: 64$ & $2: 58$ & i $2: 10$ & - & $2: 10$ & - & - & - \\
Oil & $5: 81$ & i $11: 50$ & $5: 69$ & - & - & - & - & i $5: 30$ & $5: 30$ \\
Elec. & $0: 55$ & $0: 51$ & i $1: 07$ & $0: 80$ & - & i $0: 80$ & - & $0: 64$ & i 0:64 \\
\hline
\end{tabular}


Table 9: Price elasticities in the case of designated technologies

\begin{tabular}{|l|c|c|c|}
\hline & Gas & Oil & Elec. \\
\hline \multirow{2}{*}{ Gas } & i $1: 10$ & $0: 18$ & $0: 92$ \\
& ]i $3: 16 ; 0[$ & ]0; $1: 10[$ & ]0; $2: 30[$ \\
Oil & $0: 37$ & i $1: 01$ & $0: 63$ \\
& ]0; $2: 64[$ & ]i $4: 59 ; 0[$ & ]0; $1: 98[$ \\
Electricity & $0: 36$ & $0: 15$ & i $0: 52$ \\
& ]0; $0: 76[$ & ]0; $0: 53[$ & ]i $0: 82 ; 0[$ \\
\hline
\end{tabular}

Table 10: Price elasticities in the case of $\ddagger$ exible technologies

\begin{tabular}{|l|c|c|c|}
\hline & Gas & Oil & Elec. \\
\hline \multirow{2}{*}{ Gas } & i $1: 62$ & $0: 27$ & $1: 34$ \\
& ]i $6: 11 ; 0[$ & ] $0 ; 2: 22[$ & ] $0 ; 4: 19[$ \\
Oil & $0: 61$ & i $2: 79$ & $2: 18$ \\
& ]0; $6: 53[$ & ]i $20: 93 ; 0[$ & ]0; $15: 18[$ \\
Electricity & $0: 46$ & $0: 24$ & i $0: 71$ \\
& ]0; $1: 08[$ & ]0; $0: 97[$ & ]i $1: 31 ; 0[$ \\
\hline
\end{tabular}

\section{The consequences of a carbon tax}

Following Bousquet and al. (2004), we use a tax of 30 Euro per ton of carbon. Using the carbon content of the dixerent kinds of energy, we can translate the carbon tax in price increase for each form of energy as shown in table 11.

Table 11: Carbon content of the diaerent energy forms ${ }^{14}$

\begin{tabular}{|l|r|c|}
\hline & tC/ toe & Price increase \\
\hline Gas & $0: 65$ & $+19 \%$ \\
Oil & $0: 89$ & $+26 \%$ \\
Electricity & $0: 00$ & $0 \%$ \\
\hline
\end{tabular}

Table 12 gives the changes in energy consumption and in $\mathrm{CO}_{2}$ emissions in the industrial sector resulting from the carbon tax.

\footnotetext{
${ }^{14} \mathrm{~T}$ he 0 carbon content of electricity is explained by both the high level of nuclear share in the electricity production in France and because industrial demand is mainly base load demand.
} 
Table 12: $\mathrm{CO}_{2}$ Emissions

\begin{tabular}{|l|c|c|}
\hline & Designated technology & Flexible technology \\
\hline Gas & i $17 \%$ & i $25 \%$ \\
Oil & i $24 \%$ & i $45 \%$ \\
Electricity & $+8 \%$ & $+11 \%$ \\
\hline $\mathrm{CO}_{2}$ emissions & i $20 \%$ & $\mathrm{i} 33 \%$ \\
\hline
\end{tabular}

This table shows that $\mathrm{CO}_{2}$ emissions reductions can be misestimated by one third if the hypothesis on the technology, ‡exible or designated, is wrong. For oil demand, the most pollutant energy, the misestimation is close to $50 \%$.

When the technology is considered as $\ddagger$ exible of course, the way the ..rms are distributed among the dixerent energy patterns plays an important role. As shown in table 13, there is a very important change in the fuel pattern frequencies when a carbon tax is imposed. The number of ..rms changing their fuel pattern is particularly high for those using all energy form before the energy prices changes. There are 2 times less ..rms using all forms of energy after the tax than before. Clearly, ..rms substitutes oil to gas and electricity.

Table 13: Number of ..rms following the dixerent energy patterns

\begin{tabular}{|l|r|r|}
\hline energy pattern & estimated before tax & estimated after tax \\
\hline Gas+ Oil + Elec. & 1385 & 783 \\
Oil + Elec. & 3705 & 3021 \\
Gas + Elec. & 6444 & 6907 \\
Elec. & 1211 & 2034 \\
\hline
\end{tabular}

From these results, the model choice appears as having an important consequence on the measurement of substitution possibilities between energy forms. Certainly more important than it is generally considered in the literature. As we know the level of łexibility of the technology is certainly between the two extremes assumptions we have studied in this paper. This calls for future research aiming at ..nding a new way for building model of producer behavior, and at including data on technology characteristics in energy demand modelling.

\section{Conclusion}

The present study is to our knowledge the ..rst attempt to evaluate the consequences on individual data of the usual assumptions made on energy 
technology. Using a unique data set, the French manufacturing energy consumption survey, we estimate energy technology under two extreme assumptions depending on the assumed $\ddagger$ exibility of the technology. In the literature about energy demand modeling it is well known that ..rms do not use in general all kinds of energy. Zero demands could be interpreted as zero corner solution derived from a łexible technology (Lee and Pitt 1987) or could be simply determined by the technology (Woodland 1993).

Under these two possible assumptions about the energy technology, this paper shows by how much the estimated inter-fuel substitution dixers. The dixerences between the inter-fuel substitution elasticities in the two models induce large dixerences in the predicted energy mix as a response to a change in the relative price between electricity, natural gas and oil products. This research outlines the importance of a proper estimation of inter-fuel elasticities and the consequences for greenhouse gas abatement policies.

In the real world energy technology is probably in between the two extreme assumption made in this paper. It is diф cult to keep the same framework to test a mix of these two assumptions. The reason for that is quite simple and could be shown through an example. Consider a particular ..rm with positive demands on electricity and gas. Since oil is not consumed we could consider that oil is not used because its price is too high if the technology is łexible, or we could consider alternatively that the technology do not allows the use of oil. Clearly, we have not considered all the possible cases of the underlying technology. A zero demand for oil, could occur when the ..rm have a dual ...red equipment using oil or gas and a speci..c equipment using electricity only. This example corresponds to an intermediate case of a łexible technology between oil and gas and a designated technology for electricity.

We know that with three inputs we may have seven fuel patterns. If we consider that the technology are designated, perfectly $\ddagger$ exible with respect to all inputs, or partially $\ddagger$ exible (with respect to two inputs in our case), then it is easy to see that all the observed fuel patterns could come from 14 dixerent technologies.

A problem with the Lee and Pitt's approach is that it is dic cult to extend these kinds of models when the number of inputs is larger than three. This dimension problem could be solved through simulation techniques, at the frontier of recent development in econometrics methods. But it seems to us that the main problem is that price at the individual level is not observable when the demand is zero. One way to alleviate this problem consists to extend the model and to include price estimates as function of individual characteristics.

The Woodland's approach is more simple but correct only for the estimation of short term price elasticities for ..rms owning energy technology with limited ‡exibility. Moreover, results depend on the observed fuel patterns. Since estimations are realized over each empirically relevant fuel patterns, 
results may be particularly sensitive to the level of aggregation between different kinds of energy. Finally, if fuel patterns are ..xed given the energy technology, the question about the optimal choice between some energy technologies remains. In fact, separated estimations by fuel patterns do not ensure that energy cost is optimal. Clearly in the Woodland approach's, the observed fuel pattern does not necessarily correspond to the optimal designated technology. A qualitative choice model must also be considered in order to understand how ..rms choose energy technologies in a ..rst step, and energy use in a second one.

Theoretical development in energy demand modelling will try to solve this kind of problems in the future. Moreover, a particular attention must be paid on technology characteristics in energy consumption surveys. In the same time, we need to pursue our analysis by industry sector subdivision and ..rm size, to see more precisely where the dixerences between existing alternative approaches to measure inter-fuel substitutions matter. 


\section{R eferences}

Blundell, R. and, R.J . Smith (1994). Coherency and Estimation in Simultaneous models with Censored or Qualitative Dependent Variables. J ournal of E conometrics, 64, 355-373.

Bjorner, T.B. and, H.H. J ensen (2002). Interfuel Substitution within Industrial Companies: an analysis based on panel data at company level. Energy J ournal, 23(2), 27-50.

Bousquet, A., M. Ivaldi and, N. Ladoux (1989). La demande d'énergie des industries laitières: une analyse micro-économique. E conomie et Prévision, 91(5), 75-90.

B ousquet, A. and, M. Ivaldi (1998). An Individual Choice of Energy Mix. Resource and Energy E conomics, 20, 263-286.

Bousquet A., R. Chakir and, N. Ladoux (2004). Modellling Corner Solutions with Panel Data: Application to the Industrial Energy Demand in France. forthcomming Empirical Economics.

B rowning, M. J . (1983). Necessary and Suф cient Conditions for Conditional Cost Functions. Econometrica, 51(3), 851-856.

DOE / IEA (1994). Manufacturing Consumption of Energy 1991. Energy Information A dministration, U.S. Department of Energy.

Doms, M. E. (1993). Interfuel Substitution and Energy Technology Heterogeneity in U.S. Manufacturing, Working paper 93(5), Center for Economic Studies.

Dubin, J.A. and, D.L. M CFadden (1984). An Econometric analysis of residential Electric Appliance Holdings and Consumption. Econometrica 52(2), 345-362.

Fuss, M.A. (1977). The Demand for Energy in Canadian Manufacturing: an example of the estimation of production function with many inputs. J ournal of Econometrics 5, 89-116

Griф̧ n, J .M. (1977). Inter-fuel Substitution Possibilities: a translog application to intercountry data. International Economic Review 18(3), 755770 .

Hall, V.B. (1983). Industrial Sector Interfuel Substitution Following the First Major Oil Shock. E conomics Letters 12, 377-382. 
Halvorsen, R. (1977). Energy Substitution in U.S. Manufacturing. Review of E conomics and Statistics 59(4), 381-388.

Hanemann, W.M. (1984). Discrete/ Continuous Models of Consumer Demand. E conometrica 52(3), 541-561.

Hudson, E.H. and, D. W. J orgenson (1974). U.S. Energy Policy and Economic Growth 1975-2000. B ell J ournal 5, 461-514.

J ohnson, N.L. and, S. Kotz (1973). Distributions in Statistics: Continuous Multivariate Distributions. Wiley.

Lee, L.F. and, M.M. Pitt (1986). Microeconometric Demand Systems with Binding Nonnegativity Constraints: The dual approach. Econometrica 54(5), 1237-1242.

Lee, L.F . and, M.M. Pitt (1987). M icroeconometric M odels of Rationing, Imperfect Markets, and Non-Negativity Constraints. J ournal of E conometrics, 36, 89-110.

Madlener, R. (1996). Econometric Analysis of Residential Energy Demand: A Survey. The J ournal of E conomic Literature, 2(2), 3-32.

Magnus, J.R. and A.D. Woodland, 1987, "Inter-Fuel Substitution in Dutch M anufacturing", A pplied Economics, Vol.19, 1639-1644.

Neary, J . P. and, K.W.S. Roberts (1980). The theory of household behavior under rationing. European E conomic Review 13, 25-42.

Pindyck, R.S. (1979). Inter-fuel Substitution and the Industrial Demand for Energy: an international comparison. Review of Economics and Statistics 61(2), 169-179.

Pudney, S. (1989). M odelling Individual Choice: The Econometrics of Corners, Kinks and Holes. Oxford, Blackwell.

SESSI (1997). Les consommations d'énergie de l'industrie française. Service des Statistiques Industrielles, Ministère de l'E conomie des Finances et de l'Industrie.

Squires, D. (1994). Firm Behavior Under Input Rationing. J ournal of E conometrics, 61, 235-257.

Terrell, D. (1996). Incorporating M onotonicity and Concavity Conditions in Flexible Functional Forms. J ournal of Applied Econometrics. 11, 179194. 
Thomsen, T. (2000). Short cuts to dynamic factor demand modelling. J ournal of Econometrics 97, 1-23.

Van Soest, A. V ., and P. K ooreman, 1990, "C oherency of Indirect Translog Demand System with B inding N on-N egativity Constraints", J ournal of E conometrics, 44, 391-400.

Wales, T.J . and, A.D. Woodland (1983). Estimation of consumer demand systems with binding non-negativity constraints. J ournal of Econometrics 21, 263-285.

Woodland, A.D. (1993). A M icro-E conometric Analysis of the Industrial Demand for Energy in NSW. The Energy J ournal, 14(2), 57-89. 